\title{
Intercellular Adhesion Molecule 1 Measurement
}

National Cancer Institute

\section{Source}

National Cancer Institute. Intercellular Adhesion Molecule 1 Measurement. NCI

Thesaurus. Code C124345.

The determination of the amount of intercellular adhesion molecule 1 present in a sample. 